\title{
PERCEIVED CESSATION TREATMENT EFFECTIVENESS AMONG SOCIALLY DISADVANTAGED LIGHT AND HEAVY SMOKERS
}

\author{
MAREK MILCARZ ${ }^{1}$, DOROTA KALETA ${ }^{1}$, LEOKADIA BĄK-ROMANISZYN² ${ }^{2}$, and KINGA POLAŃSKA ${ }^{1}$ \\ Medical University of Lodz, Łódź, Poland \\ ${ }^{1}$ Department of Hygiene and Epidemiology \\ ${ }^{2}$ Department of Nutrition in Digestive Tract Diseases
}

\begin{abstract}
Objectives: The aim of the current study was to assess the perceived treatment effectiveness and beliefs with respect to the best advisor who could conduct smoking cessation treatment or counseling among socially disadvantaged light and heavy smokers. This could be crucial for implementation of a successful smoking cessation intervention among this vulnerable population. Material and Methods: The current assessments were based on the data collected during the second wave of a cross-sectional study performed in the Piotrkowski District among 1668 adults aged 18-59, entitled to social aid from welfare institutions. Face-to-face interviews were conducted to collect the relevant data. Results: The current daily smoking status was declared by $31 \%$ of the participants. About $23 \%$ of the study sample ( $74 \%$ of daily smokers) admitted to being heavy smokers with a meaningful difference between men and women $(\mathrm{p}<0.05)$. About $29 \%$ of the daily smokers indicated that medications/pharmacotherapy could be a good method for giving up the habit. Fifteen percent of the participants shared the opinion that a smoking cessation specialist is the best advisor for counseling, and only about $7 \%$ would choose a general practitioner or pharmacist, and even fewer a nurse, as a person who could provide help to smokers. There were no statistically significant differences in any of the evaluated perceptions between the light and heavy smokers ( $\mathrm{p}>0.05)$. Conclusions: A high share of heavy smokers among socially disadvantaged people, and their perception that medications/pharmacotherapy would be a good solution to quit smoking, underline the need for stronger support for this method, including relevant financing resources and training. However, this method should be applied along with behavioral counseling. Int J Occup Med Environ Health. 2019;32(4):527-36
\end{abstract}

Key words:

rural area, socially disadvantaged smokers, level of smoking, perceived treatment effectiveness, smoking cessation counseling, beliefs

\section{INTRODUCTION}

Despite the fact that harmful effects of tobacco have been well-established, the worldwide age-standardized prevalence of daily smoking in 2015 amounted to $25.0 \%$ in men and $5.4 \%$ in women [1]. Those percentages are much higher in the Central and Eastern European countries, including Poland where smoking on a daily basis was declared by $27 \%$ of the adult population (including $34 \%$ of men and $21 \%$ of women) [2]. What is more, although a visible decline in the daily smoking prevalence over the last 25 years has been observed, the rate of progress for that reduction has not been consistent across genders (with small or even no decline among women) and social status (with people representing lower educational levels and socio-economic

\footnotetext{
Funding: this study was supported by Norway Grants, and co-financed from the Polish State budget (grant No. PL13-27/032/13/NMF/2015/00/2802/678 entitled "Your heart is your life - a program for reducing social inequalities in health," grant manager: Dorota Kaleta, Ph.D.) and the Medical University of Lodz (grant No. 503/6-024-01/503-66-001).

Received: January 14, 2019. Accepted: April 11, 2019.

Corresponding author: Kinga Polańska, Medical University of Lodz, Department of Hygiene and Epidemiology, Żeligowskiego 7/9, 90-752 Łódź, Poland (e-mail: kinga.polanska@umed.lodz.pl).
} 
status [SES] being at a higher risk of smoking) [1]. The results previously published by the authors, based on a cross-sectional survey conducted among social assistance beneficiaries, indicated that $37 \%$ of the respondents (including 30\% of women and 53\% of men) were current daily or occasional smokers with $>30 \%$ of them expressing willingness to quit. [3].

As pointed out by Twyman et al., there are many perceived barriers to smoking cessation in vulnerable populations, including individual and lifestyle issues, social and community barriers, living and working conditions, as well as cultural, socio-economic and environmental factors [4].

There is no doubt that tobacco dependence often requires interventions and multiple attempts at quitting. A combination of both behavioral counseling and pharmacological aids is pointed out in the current tobacco dependence treatment guidelines [5-7]. Several factors might be related to the decision not to use cessation services. Among them, the authors have recognized smokers' belief that quitting smoking is their personal responsibility, lack of necessity to seek treatment from medical professionals (as smoking is not recognized by smokers as an illness), lack of awareness of the available treatment, or misperceptions about the costs, safety and side effects of the offered medications [5,8-12].

The existing studies indicate that there are differences in the perceived cessation treatment effectiveness between light and heavy smokers [13]. For example, the analysis conducted by Nguyen et al. among the homeless has indicated that, on the one hand, light smokers were more likely to believe that group counseling would give them the greatest chance of quitting, and they were less likely to believe that medications could be helpful [13]. On the other hand, they did not differ from heavy smokers in terms of specific preferences related to a pharmacological intervention. Developing interventions in accordance with light and heavy smokers' expectations might be more cost-effective. However, the indicated preferences can be country, region or community specific.

Despite the high smoking prevalence among the disadvantaged population in Poland, there is no previous research that would examine whether treatment preferences vary by the smoking level (measured as the number of cigarettes smoked daily) [3]. Such data could be crucial for introducing a successful smoking cessation intervention among this vulnerable population.

The aim of the current study was to assess the perceived treatment effectiveness and beliefs with respect to the best advisor who could conduct smoking cessation treatment or counseling among socially disadvantaged light and heavy smokers.

\section{MATERIAL AND METHODS \\ Study design and population}

The current assessments were based on the data collected during the second wave of a cross-sectional study performed in the Piotrkowski District (a rural area in central Poland, with one of the lowest indicators of social development and Health Index) in October 2016 - February 2017 (a year after the first wave). The description of the region and the study design have been previously presented in detail [3,14-16]. Briefly, following the inclusion criteria, the study population comprised socially disadvantaged adults aged 18-59, entitled to social aid from welfare institutions of the local government (defined as those whose monthly individual income threshold did not exceed 158 USD [128 USD for family members]). The second wave of the study was conducted in order to collect data on the potential changes in the respondents' lifestyles (including smoking) and to broaden the knowledge on some further factors that might influence selected health behaviors. Of 1817 adults who participated in the first wave, 1668 agreed to take part in the interviews carried out as part of the second wave of the study $(91.8 \%)$. 
The project received an approval from the Bioethics Committee of the Medical University in Lodz (No. RNN/243/15/KE).

\section{Variables of interest}

The questionnaire was intended to collect socio-demographic (gender, age, education, employment status and subjective assessment of monthly income), health status and lifestyle related data (including the smoking status and alcohol consumption), as described previously [3,14-16]. For the purpose of the present analysis, the current daily smokers (smoking at least 1 cigarette/day over a past 30-day period) were divided into 2 categories based on the number of cigarettes smoked per day (light smokers: $<10$ cigarettes/day, heavy smokers: $\geq 10$ cigarettes/day). The daily smokers also provided information about the type of cigarettes smoked the most frequently.

Perceived cessation treatment effectiveness was assessed using the question: "Do you think the specific treatment options would give you the best chance for quitting smoking?" The following methods, similar as in other studies, were evaluated (in separate questions): group counseling, medications, both medications and group counseling, without medications or group counseling [13].

Additionally, the study participants were asked who the best advisor for performing smoking cessation treatment would be, with the following being evaluated (in separate questions): a specialist in smoking cessation, a general practitioner, a nurse and a pharmacist.

\section{Statistical analysis}

Statistical analysis was performed using the STATISTICA Windows XP version 10.0 (StatSoft Poland Inc., Tulusa, OK, USA) software package. Means and standardized deviations, as well as numbers, percentages and $95 \%$ confidence intervals $(95 \% \mathrm{CI})$ were calculated. Statistical associations of the particular characteristics categories in the analyzed subgroups of the respondents were assessed using the $\chi^{2}$ test.

Perceived cessation treatment effectiveness, the best advisor who could conduct smoking cessation treatment and the $\chi^{2}$ test of independence for the comparison between the light and heavy smokers were presented. All $p$ values were 2 -sided and $p<0.05$ was applied to indicate statistical significance.

\section{RESULTS}

\section{Description of the study population}

The second wave of the study included 1133 females (68\%) and 535 males (32\%). The majority of the respondents were $30-49$ years old, had a primary or vocational level of education $(60 \%)$, were unemployed $(60 \%)$ and assessed their monthly income as sufficient to cover basic needs only. The subjective health was rated by $70 \%$ of the respondents as fair or rather fair.

\section{Description of the smoking status declared by the respondents}

The current daily smoking status was declared by $31 \%$ of the study participants, including $23 \%$ of women and $48 \%$ of men $(\mathrm{p}<0.05)$ (Table 1$)$. Daily smokers and other participants (never smokers, former smokers and occasional smokers) differed also by age, educational level, subjective assessment of monthly income, health status and alcohol consumption ( $\mathrm{p}<0.01)$ (Table 1$)$.

About $22.7 \%$ of the sample admitted to being heavy smokers with a meaningful difference between women (15.0\% of the total population and $67 \%$ of the daily smokers) and men (38.9\% of the total population and $82 \%$ of daily smokers), $\mathrm{p}<0.05$ (Table 2). There were statistically significant gender differences in the number and type of cigarettes smoked daily (with women smoking more frequently slim and menthol cigarettes but less frequently regular cigarettes when compared to men; $\mathrm{p}<0.05)$. 
Table 1. Characteristics of the study sample of the second wave of a cross-sectional study, involving persons entitled to social aid from welfare institutions, performed in the Piotrkowski District in October 2016 - February 2017

\begin{tabular}{|c|c|c|c|c|c|c|c|}
\hline \multirow{3}{*}{ Variable } & \multicolumn{6}{|c|}{ Participants } & \multirow{3}{*}{$\mathrm{p}$} \\
\hline & \multicolumn{2}{|c|}{$\begin{array}{c}\text { total } \\
(\mathrm{N}=1668)\end{array}$} & \multicolumn{2}{|c|}{$\begin{array}{c}\text { daily smokers } \\
(\mathrm{N}=510,30.6 \%)\end{array}$} & \multicolumn{2}{|c|}{$\begin{array}{c}\text { others* } \\
(\mathrm{N}=1158,69.4 \%)\end{array}$} & \\
\hline & $\mathrm{n}$ & $\%$ & $\mathrm{n}$ & $\%$ & $\mathrm{n}$ & $\%$ & \\
\hline Sex & & & & & & & $<0.01$ \\
\hline women & 1133 & 67.9 & 255 & 22.5 & 878 & 77.5 & \\
\hline men & 535 & 32.1 & 255 & 47.7 & 280 & 52.3 & \\
\hline Age & & & & & & & $<0.01$ \\
\hline $18-29$ years & 171 & 10.3 & 46 & 26.9 & 125 & 73.1 & \\
\hline 30-39 years & 718 & 43.0 & 195 & 27.2 & 523 & 72.8 & \\
\hline 40-49 years & 552 & 33.1 & 178 & 32.2 & 374 & 67.8 & \\
\hline $50-59$ years & 224 & 13.4 & 90 & 40.2 & 134 & 59.8 & \\
\hline missing data & 3 & 0.2 & 1 & 33.3 & 2 & 66.7 & \\
\hline Education & & & & & & & $<0.01$ \\
\hline primary & 425 & 25.5 & 184 & 43.3 & 241 & 56.7 & \\
\hline vocational & 572 & 34.3 & 182 & 31.8 & 390 & 68.2 & \\
\hline secondary & 562 & 33.7 & 133 & 23.7 & 429 & 76.3 & \\
\hline high & 97 & 5.8 & 4 & 4.1 & 93 & 95.9 & \\
\hline missing data & 12 & 0.7 & 7 & 58.3 & 5 & 41.7 & \\
\hline Employment status & & & & & & & 0.08 \\
\hline permanent job & 437 & 26.2 & 114 & 26.1 & 323 & 73.9 & \\
\hline temporary job & 127 & 7.6 & 45 & 35.4 & 82 & 64.6 & \\
\hline disabled or retired & 9 & 0.5 & 4 & 44.4 & 5 & 55.6 & \\
\hline student & 3 & 0.2 & 0 & 0.0 & 3 & 100.0 & \\
\hline unemployed & 1082 & 64.9 & 345 & 31.9 & 737 & 68.1 & \\
\hline missing data & 10 & 0.6 & 2 & 20.0 & 8 & 80.0 & \\
\hline Subjective assessment of monthly income & & & & & & & $<0.01$ \\
\hline $\begin{array}{l}\text { sufficient to cover all living needs plus } \\
\text { may save a certain amount }\end{array}$ & 46 & 2.8 & 11 & 23.9 & 35 & 76.1 & \\
\hline sufficient to cover all living needs & 378 & 22.7 & 72 & 19.0 & 306 & 81.0 & \\
\hline sufficient to cover basic needs only & 808 & 48.4 & 269 & 33.3 & 539 & 66.7 & \\
\hline $\begin{array}{l}\text { not sufficient to cover even the basic } \\
\text { needs }\end{array}$ & 253 & 15.2 & 110 & 43.5 & 143 & 56.5 & \\
\hline declined response & 43 & 2.6 & 11 & 25.6 & 32 & 74.4 & \\
\hline difficult to say & 126 & 7.6 & 35 & 27.8 & 91 & 72.2 & \\
\hline missing data & 14 & 0.8 & 2 & 14.3 & 12 & 85.7 & \\
\hline
\end{tabular}


Table 1. Characteristics of the study sample of the second wave of a cross-sectional study, involving persons entitled to social aid from welfare institutions, performed in the Piotrkowski District in October 2016 - February 2017 - cont.

\begin{tabular}{|c|c|c|c|c|c|c|c|}
\hline \multirow{3}{*}{ Variable } & \multicolumn{6}{|c|}{ Participants } & \multirow{3}{*}{$\mathrm{p}$} \\
\hline & \multicolumn{2}{|c|}{$\begin{array}{c}\text { total } \\
(\mathrm{N}=1668)\end{array}$} & \multicolumn{2}{|c|}{$\begin{array}{c}\text { daily smokers } \\
(\mathrm{N}=510,30.6 \%)\end{array}$} & \multicolumn{2}{|c|}{$\begin{array}{c}\text { others* } \\
(\mathrm{N}=1158,69.4 \%)\end{array}$} & \\
\hline & $\mathrm{n}$ & $\%$ & $\mathrm{n}$ & $\%$ & $\mathrm{n}$ & $\%$ & \\
\hline Subjective health status & & & & & & & $<0.01$ \\
\hline fair & 605 & 36.3 & 160 & 26.4 & 445 & 73.6 & \\
\hline rather fair & 566 & 33.9 & 165 & 29.2 & 401 & 70.8 & \\
\hline neither fair nor poor & 305 & 18.3 & 110 & 36.1 & 195 & 63.9 & \\
\hline rather poor & 133 & 8.0 & 51 & 38.3 & 82 & 61.7 & \\
\hline poor & 34 & 2.0 & 17 & 50.0 & 17 & 50.0 & \\
\hline missing data & 25 & 1.5 & 7 & 28.0 & 18 & 72.0 & \\
\hline Alcohol consumption & & & & & & & $<0.01$ \\
\hline do not drink at all & 730 & 43.8 & 177 & 24.2 & 553 & 75.8 & \\
\hline moderate drinking and heavy drinking & 372 & 22.3 & 120 & 32.3 & 252 & 67.7 & \\
\hline missing data & 566 & 33.8 & 213 & 37.6 & 353 & 62.4 & \\
\hline
\end{tabular}

* Never smokers, former smokers and occasional smokers.

\section{Perceived cessation treatment effectiveness}

and the opinion about the advisor who could conduct smoking cessation treatment and counseling

About $29 \%$ of the daily smokers interviewed selected medications/pharmacotherapy, and only $7 \%$ both medications/ pharmacotherapy and counseling, as a good method for quitting the habit (Table 3). However, $16 \%$ of the smokers believed that unaided quitting attempts represented their best chance for quitting. Fifteen percent of the study participants shared the opinion that a specialist in smoking cessation would be a good advisor for treatment, and only about $7 \%$ would choose a general practitioner and a pharmacist, and even fewer a nurse $(2.3 \%)$, as a person who could provide help to smokers. There were no statistically significant differences in any of the evaluated perceptions between the light and heavy smokers $(\mathrm{p}>0.05)$.

\section{DISCUSSION}

Results of this cross-sectional study underline the high prevalence of daily smoking among the socially disad- vantaged population from a rural area in Poland. What is more, about three-fourths of those who declared the current smoking status were classified as heavy smokers based on the number of cigarettes smoked per day. One-third of the respondents selected medications/pharmacotherapy, and a much smaller percentage both medications/pharmacotherapy and counseling, as a good method for quitting the habit. A specialist in smoking cessation was indicated as the best professional who could provide help to smokers, following a general practitioner and a pharmacist. It is also worth noting that the people who smoked $<10$ cigarettes/day did not significantly differ from the heavy smokers with regard to the specific pharmacological intervention preferences or perceived the best advisor for smoking treatment. The results indicate that more attention should be paid to pharmacological aids, including relevant promotion, funding and training of professionals who could deliver that type of treatment.

The share of smokers among the social care beneficiaries from a rural district is higher than that for the general 


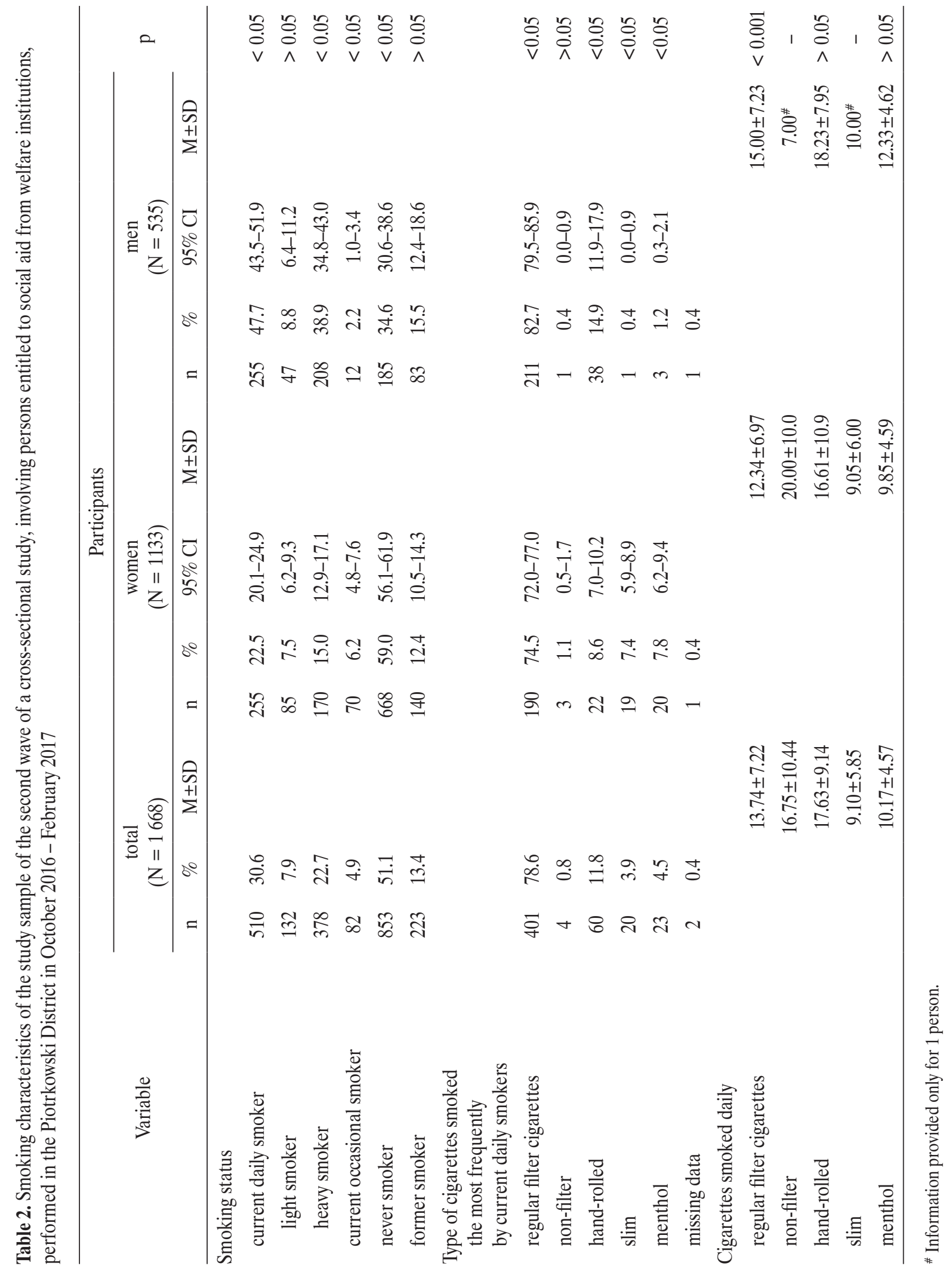


Table 3. Perceived cessation treatment effectiveness and the best advisor who can conduct smoking cessation treatment or counseling, according to the participants of the second wave of a cross-sectional study, entitled to social aid from welfare institutions, performed in the Piotrkowski District in October 2016 - February 2017

\begin{tabular}{|c|c|c|c|c|c|c|c|c|c|}
\hline \multirow{3}{*}{ Variable } & \multicolumn{8}{|c|}{ Participants } & \multirow{3}{*}{$\mathrm{p}$} \\
\hline & \multicolumn{2}{|c|}{$\begin{array}{c}\text { total } \\
(\mathrm{N}=510)\end{array}$} & \multicolumn{3}{|c|}{$\begin{array}{l}\text { light smokers } \\
(\mathrm{N}=132)\end{array}$} & \multicolumn{3}{|c|}{$\begin{array}{l}\text { heavy smokers } \\
\qquad(\mathrm{N}=378)\end{array}$} & \\
\hline & $\mathrm{n}$ & $\%$ & $\mathrm{n}$ & $\%$ & $95 \% \mathrm{CI}$ & $\mathrm{n}$ & $\%$ & $95 \% \mathrm{CI}$ & \\
\hline \multicolumn{10}{|l|}{ The best chance for quitting (yes) } \\
\hline medications/pharmacotherapy & 147 & 28.8 & 28 & 21.2 & $14.2-28.2$ & 119 & 31.5 & $26.8-36.2$ & $>0.05$ \\
\hline group counseling & 21 & 4.1 & 9 & 6.8 & $2.5-11.1$ & 12 & 3.2 & $1.4-5.0$ & $>0.05$ \\
\hline both medications and counseling & 37 & 7.3 & 13 & 9.8 & $4.7-14.9$ & 24 & 6.4 & $3.9-8.9$ & $>0.05$ \\
\hline without medications or counseling & 82 & 16.1 & 34 & 25.8 & $7.0-28.4$ & 48 & 12.7 & $9.3-16.1$ & $>0.05$ \\
\hline \multicolumn{10}{|l|}{$\begin{array}{l}\text { The best advisor for smoking cessation } \\
\text { treatment or counseling (yes) }\end{array}$} \\
\hline smoking cessation specialist & 78 & 15.3 & 26 & 19.7 & $12.9-26.5$ & 52 & 13.8 & $10.3-17.3$ & $>0.05$ \\
\hline general practitioner & 32 & 6.3 & 14 & 10.6 & $5.4-15.9$ & 18 & 4.8 & $2.6-7.0$ & $>0.05$ \\
\hline nurse & 12 & 2.3 & 4 & 3.0 & $0.1-5.9$ & 8 & 2.1 & $0.6-3.4$ & $>0.05$ \\
\hline pharmacist & 34 & 6.7 & 10 & 7.6 & $3.1-12.1$ & 24 & 6.4 & $3.9-8.9$ & $>0.05$ \\
\hline other & 12 & 2.3 & 4 & 3.0 & $0.1-5.9$ & 8 & 2.1 & $0.6-3.6$ & $>0.05$ \\
\hline
\end{tabular}

population in Poland, especially among men. Details regarding these differences, their interpretation and similarity to other studies in this field [17-23] have been published elsewhere [3]. As it was mentioned before, the current assessments were based on the participants from the second wave of the study. Comparing the data obtained within the first and the second waves of the study, there were no differences in the percentages of daily smokers (30.8\% vs. $30.6 \%, \mathrm{p}>0.05$ ). However, a smaller percentage of occasional smokers was observed in the subsequent interview (4.9 vs. 6.3, $\mathrm{p}<0.05$ ) [3]. This can be explained by the scope of the study which included some educational tools focusing on the most important risk factors for non-communicable diseases (including smoking). It could be suspected that some part of occasional smokers quit smoking after this educational campaign. However, underreporting cannot be excluded.

The study participants expressed their perception that medications/pharmacotherapy would be the best choice for quitting. This can be crucial not only from the perspec- tive that pharmacological aid is recommended for heavy smokers (and in this study that kind of treatment was more frequent, though not significant, among the heavy comparing to light smokers) but also taking into the account daily barriers to cessation, including exposure to other smokers, high stress and difficult living, as well as working conditions among the socially disadvantaged people $[4,24,25]$. The authors' results indicate that more attention should be paid to pharmacological aids compliant with the population's expectations. That should cover relevant promotion, funding resources and training of professionals who can deliver that type of treatment. However, according to the existing tobacco dependence guidelines, pharmacological treatment should be combined with non-pharmacological cessation aids [5]. Further education in this field is necessary, considering the observation from this study that only $7 \%$ of the study participants indicated both types of treatment as the best chance for quitting. The observed percentages for this option are much smaller than those in the study by Nguyen et al. [13]. 
The socially disadvantaged participants shared the opinion that a specialist in smoking cessation would be the best advisor for treatment. Taking this into account, smoking cessation clinics need to be promoted more intensively, and should be easily accessible, at low or no costs, especially in the case of people with a lower SES. Additionally, the respondents felt as positive about pharmacists as cessation resources as they did about physicians. This can result from the fact that pharmacists are easily accessible and affordable. Such information is crucial for decision makers to put more effort in incorporating smoking cessation educations/campaigns in pharmacies. That needs to go in line with providing the information where the smokers can find more professional help in quitting, and increasing the role of general practitioners who could provide tobacco treatment.

This study indicated a prevalent perception that quitting without medications and counseling would yield the best results, with a higher, though not statistically significant, percentage expressing this opinion among the light than heavy smokers. This is in agreement with the results of the study conducted among homeless smokers [13]. Based on the existing research, the willpower, desire and commitment to quit are listed as requirements for successful quitting [5]. What is more, smokers frequently believe that they can quit smoking without any help, which exemplifies the values of their independence and self-reliance, and enables them to feel that they achieved something without aids [5]. In addition, as it was mentioned previously, some smokers did not recognize their habit as a disease and, thus, they did not think that any help in a form of nicotine replacement therapy (NRT) or other pharmacological aids, or behavioral counseling was needed. Finally, they can be insufficiently aware of the available methods of treatment. All of these perceptions underline the need for education on the cessation aids available and their place in therapy.

For the first time, information about perceived cessation treatment effectiveness and beliefs with regard to the pro- fessional who could help in quitting smoking has been collected among social care beneficiaries from a rural district in Poland. That information is crucial for interventions and cessation programs among these socially disadvantaged people, with a strengthened promotion of pharmacotherapy to address cravings. It also needs to be pointed out that the authors obtained about a $50 \%$ participation rate in the first wave and $>90 \%$ in the second wave of the study. In addition, the interviewer-administered questionnaires, comparing to self-administered ones, produced higher values of sensitivity and specificity.

Limitations of the study, as mentioned in previous publications released by the authors, could be related to the cross-sectional study design, the lack of generalizability of the findings (as the study covered the disadvantaged people from one rural area in Poland) or the lack of verification of the smoking status (which is difficult to perform in big cross-sectional surveys) [3]. Taking into account that the data were based on self-reports, the response bias cannot be excluded. However, the likelihood of the response bias was assumed to be minimal since the survey was conducted as face-to-face interviews.

\section{CONCLUSIONS}

A high share of heavy smokers among socially disadvantaged people, and their perception that medications/pharmacotherapy would be the best choice for quitting smoking, underline the need for a stronger support for this method, including relevant financing and training. However, this method should be applied along with behavioral counseling.

\section{REFERENCES}

1. GBD 2015 Tobacco Collaborators. Smoking prevalence and attributable disease burden in 195 countries and territories, 1990-2015: a systematic analysis from the Global Burden of Disease Study 2015. Lancet. 2017;389(10082):1885-906, https://doi.org/10.1016/S0140-6736(17)30819-X. 
2. The Maria Skłodowska-Curie Cancer Center and Institute of Oncology, Medical University of Warsaw, Centers for Disease Control and Prevention. Global Adult Tobacco Survey Poland 2009-2010. Warsaw: Ministry of Health; 2010 [cited 2019 Jan 25]. Available from: http://www.who.int/tobacco/surveillance/ en_tfi_gats_poland_report_2010.pdf.

3. Milcarz K, Makowiec-Dabrowska T, Bak-Romaniszyn L, Kaleta D. Smoking patterns and smoking cessation willingness - A study among beneficiaries of government welfare assistance in Poland. Int J Environ Res Public Health. 2017;14(2):131, https://doi.org/10.3390/ijerph14020131.

4. Twyman L, Bonevski B, Paul C, Bryant J. Perceived barriers to smoking cessation in selected vulnerable groups: a systematic review of the qualitative and quantitative literature. BMJ Open. 2014;4(12):e006414, https://doi.org/10.1136/bmjopen-2014-006414.

5. Abelleira AA, Morrill AM, Abel C, Goldsmith CA. Perception and Use of Smoking Cessation Methods Stratified by Patient Characteristics: A Pilot Study. Ann Public Health Resh. 2018;5(3):1082.

6. Caraballo RS, Shafer PR, Patel D, Davis KC, McAfee TA. Quit Methods Used by US Adult Cigarette Smokers, 2014-2016. Prev Chronic Dis. 2017;14:160600, https://doi. org/10.5888/pcd14.160600.

7. Fiore MC, Jaén CR, Baker TB, Bailey WC, Benowitz NL, Curry SJ, et al. Treating tobacco use and dependence: 2008 update. Clinical practice guideline. Rockville: US Department of Health and Human Services, Public Health Service; 2008 [cited 2019 Jan 25]. Available from: https://www.ncbi. nlm.nih.gov/books/NBK63952/.

8. Morphett K, Partridge B, Gartner C, Carter A, Hall W. Why Don't Smokers Want Help to Quit? A Qualitative Study of Smokers' Attitudes towards Assisted vs. Unassisted Quitting. Int J Environ Res Public Health. 2015;12(6):6591-607, https://doi.org/10.3390/ijerph120606591.

9. Morphett K, Lucke J, Gartner C, Carter A, Meurk C, Hall W. Public attitudes toward the treatment of nicotine addiction. Nicotine Tob Res. 2013;15(9):1617-22, https://doi.org/10.1093/ntr/ntt037.
10. Hammond D, McDonald PW, Fong GT, Borland R. Do smokers know how to quit? Knowledge and perceived effectiveness of cessation assistance as predictors of cessation behaviour. Addiction. 2004;99(8):1042-8, https://doi. org/10.1111/j.1360-0443.2004.00754.x.

11. Smith AL, Carter SM, Dunlop SM, Freeman B, Chapman S. The views and experiences of smokers who quit smoking unassisted. A systematic review of the qualitative evidence. PLoS One. 2015;10(5):e0127144, https://doi.org/10.1371/ journal.pone.0127144.

12. Smith AL, Carter SM, Chapman S, Dunlop SM, Freeman B. Why do smokers try to quit without medication or counselling? A qualitative study with ex-smokers. BMJ Open. 2015;5(4):e007301, https://doi.org/10.1136/bmjopen-2014-00 7301.

13. Nguyena MH, Reitzel LR, Kendzorc DE, Businelle MS. Perceived cessation treatment effectiveness, medication preferences, and barriers to quitting among light and moderate/heavy homeless smokers. Drug Alcohol Depend. 2015;153:341-5, https://doi.org/10.1016/j.drugalcdep. 2015.05.039.

14. Milcarz K, Bak-Romaniszyn L, Kaleta D. Environmental Tobacco Smoke Exposure and Smoke-Free Rules in Homes among Socially-Disadvantaged Populations in Poland. Int J Environ Res Public Health. 2017;14(4):447, https://doi. org/10.3390/ijerph14040447.

15. Milcarz M, Polańska K, Bak-Romaniszyn L, Kaleta D. How Social Care Beneficiaries in Poland Rate Relative Harmfulness of Various Tobacco and Nicotine-Containing Products. Int J Environ Res Public Health. 2017;14(9):1029, https:// doi.org/10.3390/ijerph14091029.

16. Milcarz M, Polanska K, Bak-Romaniszyn L, Kaleta D. Tobacco Health Risk Awareness among Socially Disadvantaged People - A Crucial Tool for Smoking Cessation. Int J Environ Res Public Health. 2018;15(10):E2244, https://doi. org/10.3390/ijerph15102244.

17. Siahpush M, Borland R, Scollo M. Health Inequalities: Prevalence and socio-economic correlates of smoking 
among lone mothers in Australia. Aust NZ J Public Health. 2002;26(2):132-5, https://doi.org/10.1111/j.1467-842x.2002.tb 00905.x.

18. Johnson TP, Barrett ME. Substance use and treatment needs among homeless persons in Cook County Illinois. Int J Ment Health Addict. 1995;30(5):557-85, https://doi. org/10.3109/10826089509048744.

19. Connor SE, Cook RL, Herbert MI, Neal SM, Williams JT. Smoking cessation in a homeless population: There is a will, but is there a way? J Gen Intern Med. 2002;17(5):369-72, https://doi.org/10.1046/j.1525-1497.2002.10630.x.

20. De Leon J, Diaz FJ. A meta-analysis of worldwide studies demonstrates an association between schizophrenia and tobacco smoking behaviors. Schizophr Res. 2005;76(2-3):13557, https://doi.org/10.1016/j.schres.2005.02.010.

21. Lasser K, Boyd JW, Woolhandler S, Himmelstein DU, McCormick D, Bor DH. Smoking and mental illness: A po- pulation-based prevalence study. JAMA. 2000;284:2606-10, https://doi.org/10.1001/jama.284.20.2606.

22. Baggett TP, Rigotti NA. Cigarette smoking and advice to quit in a national sample of homeless adults. Am J Prev Med. 2010;39(2):164-72, https://doi.org/10.1016/j.amepre. 2010.03.024.

23. Kermode M, Crofts N, Miller P, Speed B, Streeton J. Health indicators and risks among people experiencing homelessness in Melbourne, 1995-1996. Aust NZ J Public Health. 1998;22(4): 464-70, https://doi.org/10.1111/j.1467-842x.1998.tb01415.x.

24. Baggett TP, Tobey ML, Rigotti NA. Tobacco use among homeless people - addressing the neglected addiction. $\mathrm{N}$ Engl J Med. 2013;369:201-4, https://doi.org/10.1056/nejmp1301935.

25. Businelle, MS, Cuate, EL, Kesh A, Poonawalla IB, Kendzor DE. Comparing homeless smokers to economically disadvantaged domiciled smokers. Am J Public Health. 2013; 103(2):218-20, https://doi.org/10.2105/ajph.2013.301336.

This work is available in Open Access model and licensed under a Creative Commons Attribution-NonCommercial 3.0 Poland License - http://creativecommons.org/ licenses/by-nc/3.0/pl/deed.en. 